\section{Thermal Cleavage of the Fmoc Protection Group}

Stefan Höck ${ }^{\star a}$, Roger Marti ${ }^{\mathrm{b}}$, Rainer Riedla ${ }^{\mathrm{a}}$, and Marina Simeunovic ${ }^{c}$

${ }^{*}$ Correspondence: Dr. S. Höck ${ }^{a}$, Tel.: +4158934 5574,

E-mail: stefan.hoeck@zhaw.ch,

aZHAW Zurich University of Applied Sciences, Institute of Chemistry and

Biological Chemistry (ICBC), Campus Reidbach, Einsiedlerstrasse 31,

$\mathrm{CH}-8820$ Wädenswil

'Ecole d'Ingénieurs et d'Architectes de Fribourg, Département des Technologies Industrielles, Filière de Chimie, Bd de Pérolles 80, CH-1705 Fribourg

'Part of MS's Bachelor thesis, Current Address: Empa Dübendorf,

Überlandstrasse 129, CH-8600 Dübendorf

Abstract: The Fmoc protection group is among the most commonly used protection groups for the amino function. A fast method for the thermal deavage of this protection group under base-free conditions without the need for dibenzofulvene scavengers is presented. The advantages of this method include straightforward testability by means of a simple high-temperature NMR experiment, usually high yields, and good selectivity towards the $\mathrm{BOC}$ protection group and $t$-butyl ethers.

Keywords: Dibenzofulvene - Fmoc protection group · High-temperature NMR - Peptide synthesis · Thermal cleavage

\section{Introduction}

\subsection{The Fmoc Protection Group}

The Fmoc (fluorenylmethoxy carbonyl) protection group is among the most commonly used protection groups for the amino function especially in solid-phase peptide synthesis (for a review, see ref. [1]). It can be easily introduced by coupling an amine with an activated 9-fluorenylmethyl carbonate like $\mathrm{Fmoc}-\mathrm{Cl},{ }^{[2]}$ Fmoc-OSu, ${ }^{[3]}$ or Fmoc-OBt.[3a,b] One major advantage of the Fmoc group is its stability towards acidic conditions, which allows the selective removal of other protection groups like BOC ( $t$-butyl carbamate) in the presence of strong acids. The Fmoc group can be easily cleaved by using amine bases such as $20 \%$ piperidine or $50 \%$ morpholine in DMF. ${ }^{1]}$ Since Fmoc cleavage results in the liberation of a primary or secondary amine, autocatalytic decomposition of the Fmoc group in only slightly basic environments has been observed.[4]

\subsection{Dynamic Effects of the Carbamate Group in NMR Experiments}

One peculiarity of carbamate and amide groups is their high rotational barrier for the rotation around the $\mathrm{C}(\mathrm{O})-\mathrm{N}$ bond. In NMR spectroscopy this usually leads to a broadening or even doubling of at least some of the molecule's signals due to the longevity of the two major rotamers (Fig. 1). The occurrence of such dynamic effects can be circumvented by increasing the sample temperature during the NMR measurement. Usually, temperatures of $100{ }^{\circ} \mathrm{C}$ and above are needed to observe a single set of sharp signals.

During such a high-temperature experiment in d6-DMSO we observed that the Fmoc protection was neatly cleaved within $10 \mathrm{~min}$ at $120{ }^{\circ} \mathrm{C}$ without any amine base being present in the mixture. Further investigation revealed a facile method for the

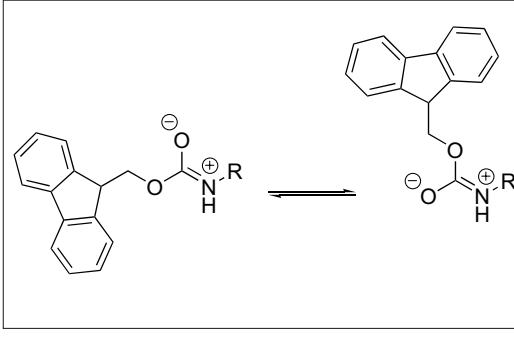

Fig. 1. The two major rotamers of the carbamate group.

base-free cleavage of the Fmoc group that can easily be tested for any given substance with a simple high-temperature NMR experiment. This method is also applicable in the presence of free carbonic acid groups, where the $\mathrm{pH}$ of the reaction mixture is slightly acidic throughout the whole reaction.

\section{Results and Discussion}

\subsection{Preliminary Testing in High-temperature NMR Experiments}

The applicability of the thermal Fmoc cleavage for a given molecule was at first tested for each substrate in a high-temperature NMR experiment by dissolving the Fmoc-protected amine in d6-DMSO and keeping the solution at a sample temperature of $120{ }^{\circ} \mathrm{C}$. The reaction's progress was monitored by comparison of the increasing signal of the olefinic hydrogen atoms of dibenzofulvene ( $s$ at $6.21 \mathrm{ppm}$ ) with the signals of the aromatic hydrogen atoms (7 - 8 ppm; Fig. 2).

\subsection{Solvent Effects and Mechanistic Aspects}

In a first set of experiments, the role of the solvent in the thermal cleavage of the Fmoc group was investigated. At 120 ${ }^{\circ} \mathrm{C}$ quantitative cleavage of the Fmoc group from FmocProOH (Fmoc-L-proline) was observed after $15 \mathrm{~min}$ in DMF, NMP (N-

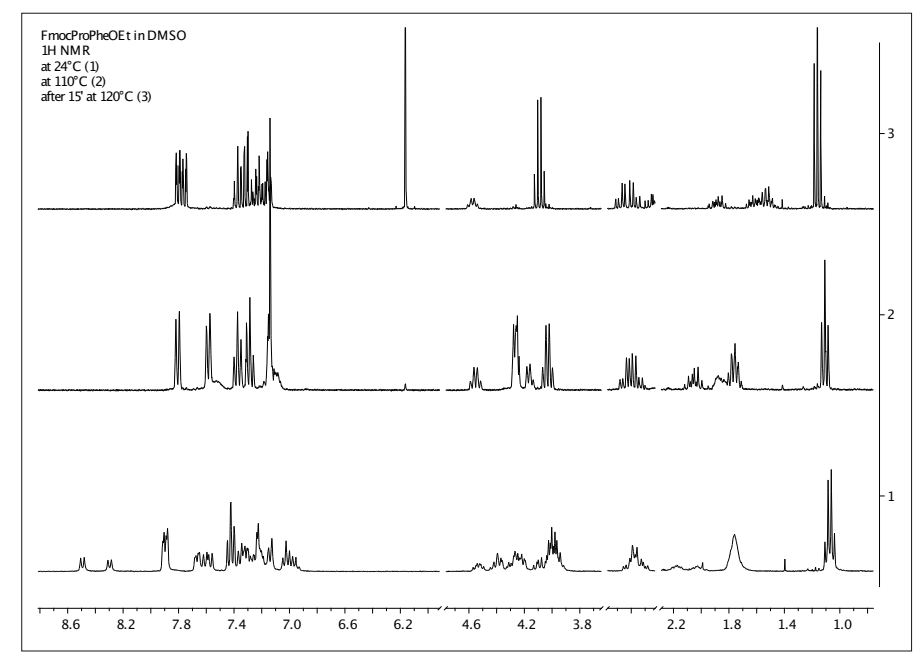

Fig. 2. Selected regions of the ${ }^{1} \mathrm{H}-\mathrm{NMR}$ spectrum of FmocProPheOEt at 1) $24^{\circ} \mathrm{C}$; 2) $110^{\circ} \mathrm{C}$; 3) after $15 \mathrm{~min}$ at $120^{\circ} \mathrm{C}$. Note the increase in intensity of the signal at $6.2 \mathrm{ppm}$, resulting from the olefinic hydrogen atoms of dibenzofulvene. 
Table 1. Fmoc cleavage in different solvents after $15 \mathrm{~min}$ at $120^{\circ} \mathrm{C}$

$\begin{array}{ll}\text { Solvent } & \text { Fmoc Cleaved [\%] }{ }^{\mathrm{a}} \\ \text { DMSO } & >95 \\ \mathrm{DMF} & >95 \\ \mathrm{NMP} & >95 \\ \text { Acetonitrile } & \sim 60 \\ \text { Chlorbenzene } & 0 \\ \mathrm{CHCl}_{3} & 0 \\ \mathrm{MeOH}^{\mathrm{a}} & 0 \\ { }^{a} \text { Determined by }{ }^{1} \mathrm{H}-\mathrm{NMR} \text { spectroscopy }\end{array}$

methyl pyrrolidone), and DMSO respectively. In acetonitrile, the reaction was somewhat slower, while no reaction was observed in chloroform, methanol, or chlorbenzene (Table 1).

In chlorbenzene, FmocProOH was quantitatively cleaved after $15 \mathrm{~min}$ at $150{ }^{\circ} \mathrm{C}$. We therefore assume two different mechanisms for the cleavage depending on the solvent. In both cases we assume an en-type decomposition (pyrolysis) as shown in Scheme 1. In dipolar aprotic solvents like DMSO or DMF, which lead to Fmoc cleavage at lower temperatures, the solvent might to a certain degree participate in an $\mathrm{E} 1_{\mathrm{CB}}$ mechanism as displayed in Scheme 2. In both cases the liberated amine will participate in the cleavage reaction leading to an autocatalyzed decomposition that has been described before by Arimitsu and Ichimura. ${ }^{[4]}$

\subsection{Avoiding Side Reactions of Dibenzofulvene}

A problem often encountered when cleaving Fmoc-groups are side reactions with the liberated dibenzofulvene (1), which is sometimes rendered inactive by adding a scavenger such as $n$ octane thiole. ${ }^{[5]}$ During our high-temperature NMR experiments we observed neither polymerization of the liberated dibenzofulvene nor any kind of Michael-addition of the free amine to dibenzofulvene. Such side reactions were only observed when evaporating the solvents or during purification of the raw product by silica gel chromatography. We therefore tested a set of workup procedures that can be used to remove dibenzofulvene from the reaction mixture without the need to first evaporate the solvent. For solid products such as proline, it usually suffices to add an excess of $t$-butylmethyl ether (TBME) to the cold reaction mixture, which leads to precipitation of the product while dibenzofulvene remains in solution. Dibenzofulvene-free products can then be isolated by filtration. Water-soluble products can be purified by extraction with water/TBME where dibenzofulvene remains in the organic layer. In some reactions it proved useful to dilute the reaction mixture with TBME and transform the free amine to its HCl-salt, which then precipitated. Each of these workupprocedures circumvents the need for a dibenzofulvene scavenger.

\subsection{Preparative Aspects}

Although the reaction is fast and clean when heating the reaction mixture by microwave irradiation, one must be careful when carrying out the reaction in closed vessels at larger scales due to the formation of an equimolar amount of $\mathrm{CO}_{2}$. In some microwave devices the rapid pressure increase at the beginning of the reaction could lead to an emergency stop.

Table 2 shows the substrates for which the thermal cleavage method was tested. In most cases, Fmoc cleavage was almost quantitative after $10-15$ minutes at $120{ }^{\circ} \mathrm{C}$. Only in the case of FmocPheSer(tBu)OH were longer reaction times needed to achieve quantitative cleavage. In the case of FmocTrp(BOC)OH about $50 \%$ of the BOC protection groups were also cleaved (determined by ${ }^{13} \mathrm{C}$-NMR) while in the case of FmocLys(BOC)OH the $\mathrm{BOC}$ protection group was not affected. Alcohols protected as their $t$-butyl ether were not affected under these conditions.

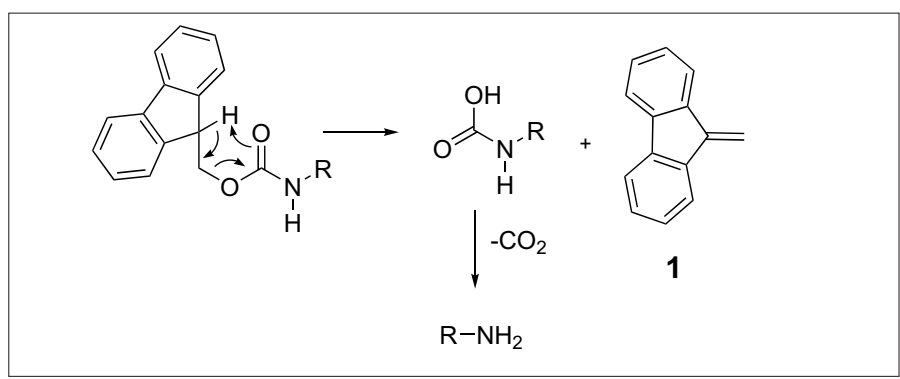

Scheme 1. Fmoc cleavage by an en-type mechanism.

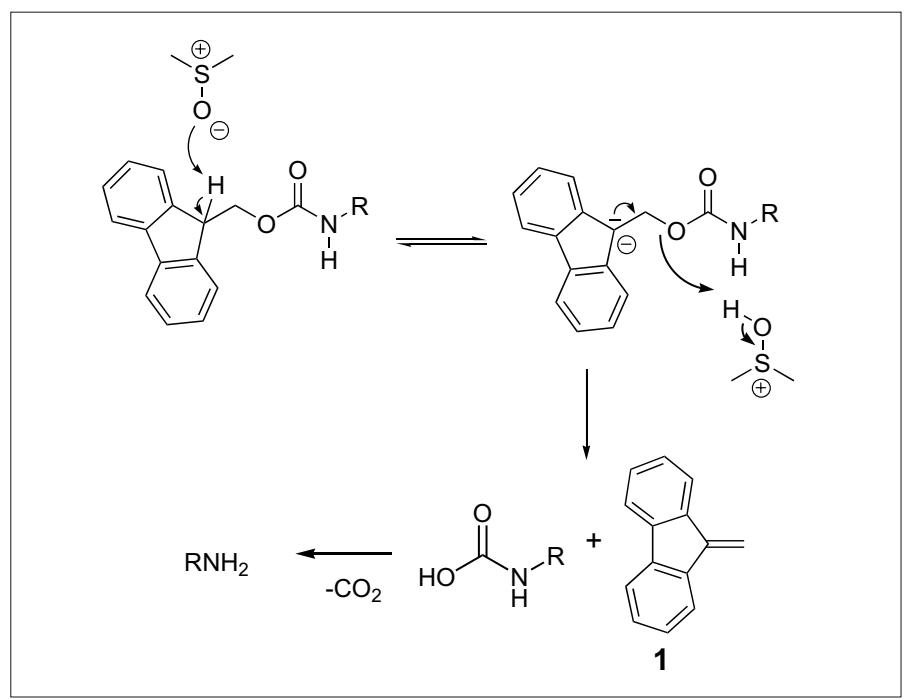

Scheme 2. Fmoc cleavage by an $\mathrm{E}_{\mathrm{CB}}$ mechanism.

DMSO seemed to be the best solvent for this reaction since DMF often contains a certain amount of free amine bases, which might lead to epimerization of peptides at higher temperatures.

\section{Conclusion and Outlook}

A facile and clean method for Fmoc-deprotection without the need for an excess of hard-to remove bases was presented. The reaction at $120{ }^{\circ} \mathrm{C}$ in d6-DMSO could easily be monitored in a short high-temperature NMR experiment and usually led to

Table 2. Thermal Fmoc cleavage of different substrates. All yields are isolated yields at a scale of $150 \mathrm{mg}$. Purity and identity of the products were determined by ${ }^{1} \mathrm{H}$ - and ${ }^{13} \mathrm{C}-\mathrm{NMR}$.

$\begin{array}{lll}\text { Substrate } & \text { Reaction Time } & \text { Fmoc cleavage } \\ \text { FmocProOH } & 15 \mathrm{~min} & 96 \% \\ \text { FmocTrp(BOC)OH } & 20 \mathrm{~min} & \sim 50 \% \text { BOC cleavage } \\ \text { FmocLys(BOC)OH } & 15 \mathrm{~min} & 96 \% \\ \text { FmocValOH } & 15 \mathrm{~min} & 88 \% \\ \text { FmocThr }(t \mathrm{Bu}) \mathrm{OH} & 15 \mathrm{~min} & 85 \% \\ \text { FmocAsp }(t \mathrm{Bu}) \mathrm{OH} & 15 \mathrm{~min} & 88 \% \\ \text { Fmoc- } \beta-\mathrm{HomoleuOH} & 15 \mathrm{~min} & 91 \% \\ \text { Fmoc- } \beta- & 15 \mathrm{~min} & 97 \% \\ \text { HomopheOH } & 10 \mathrm{~min} & 91 \% \\ \text { FmocLeuProOH } & 3 \mathrm{~h} & 95 \% \\ \text { FmocPheSer }(t \mathrm{Bu}) \mathrm{OH} & \end{array}$


quantitative Fmoc cleavage after just 10-15 minutes. Our next step will be to further investigate the applicability of this method in liquid-phase multi-step peptide synthesis.

\section{Experimental}

\subsection{Hardware}

All NMR experiments were carried out on a $300 \mathrm{MHz}$ Avance Bruker NMR device using deuterated solvents from Armar Chemicals. High-temperature experiments were carried out at $120{ }^{\circ} \mathrm{C}$ with relaxation delay values (D1) of 4 to $8 \mathrm{sec}$ for ${ }^{1} \mathrm{H}-$ NMR spectra. Chemical shifts are given in ppm and coupling constants $(J)$ in $\mathrm{Hz}$ in descending order.

For mg-scale cleavage experiments reaction mixtures were heated by microwave irradiation in a Biotage Initiator microwave device. Optical rotation values were measured on a Perkin Elmer 341 polarimeter. Melting points were measured on a Büchi B-540 melting point device and are not corrected. In all experiments, analytical grade chemicals from Fluka and Bachem were used.

\subsection{Fmoc Cleavage in an NMR Tube}

The Fmoc-protected amino acid or peptide ( $c a .10 \mathrm{mg}$ ) was dissolved in d6-DMSO $(0.7 \mathrm{ml})$ in a $5 \mathrm{~mm}$ NMR tube and heated to $120^{\circ} \mathrm{C}$ - either in an oil bath or directly in the NMR-probe. The progress of the reaction was monitored by comparing the increasing intensity of the singlet at $6.2 \mathrm{ppm}$ resulting from the terminal double bond of dibenzofulvene with the remaining signals in the aromatic region (6-8 ppm).

Dibenzofulvene (1): ${ }^{1} \mathrm{H}$ NMR (300 MHz, DMSO) $\delta 7.85$ (ddd, $J=7.4,1.3,0.8,2 \mathrm{H}), 7.80$ (ddd, $J=7.5,1.3,0.8,2 \mathrm{H}), 7.41$ $(\mathrm{td}, J=7.4,1.3,2 \mathrm{H}), 7.34(\mathrm{td}, J=7.4,1.3,2 \mathrm{H}), 6.21(\mathrm{~s}, 2 \mathrm{H})$.

\subsection{Small-Scale Cleavage Procedure}

The Fmoc-protected amino acid or peptide $(150 \mathrm{mg})$ was dissolved in DMSO $(0.6 \mathrm{ml})$. The reaction mixture was then heated to $120^{\circ} \mathrm{C}$ by microwave irradiation in a closed vessel for $15 \mathrm{~min}$. In most cases, after cooling down, a white solid precipitated from the reaction mixture. TBME $(2 \mathrm{ml})$ was added and the mixture was filtered through a suction filter. The precipitate was then dried under high vacuum.

\subsection{Gram-Scale Cleavage of FmocProOH}

FmocProOH (3.00 g, $8.89 \mathrm{mmol})$ was dissolved in DMSO (5 $\mathrm{ml}$ ) and the mixture was stirred at $120^{\circ} \mathrm{C}$ in an oil bath for $20 \mathrm{~min}$ until no more gas formation was observed. After cooling a white solid precipitated. TBME $(20 \mathrm{ml})$ was added and the mixture was filtered through a suction filter and washed twice with TBME $(10 \mathrm{ml})$. The precipitate was dried under reduced pressure and L-proline was isolated as a white solid (0.98 g, $8.51 \mathrm{mmol}, 96 \%)$.

L-Proline: ${ }^{1} \mathrm{H}$ NMR (300 MHz, DMSO at $\left.70{ }^{\circ} \mathrm{C}\right): 5.0-4.0$ (br. $s, 2 \mathrm{H}) ; 3.66(d d, J=8.4,5.8,1 \mathrm{H}) ; 3.24(d d d, J=11.2,7.3$, $5.8,1 \mathrm{H}) ; 3.03(d t, J=11.2,7.5,1 \mathrm{H}) ; 2.01(\mathrm{~m}, 2 \mathrm{H}) ; 1.78(\mathrm{~m}$, $2 \mathrm{H})$. m.p.: $221-227{ }^{\circ} \mathrm{C}$ (decomposition) (Lit: $224-226{ }^{\circ} \mathrm{C}^{[6]}$ ). $[\alpha]_{\mathrm{D}}:-82.1^{\circ}\left(\mathrm{c} 0.1, \mathrm{H}_{2} \mathrm{O}\right)\left(\mathrm{Lit}:-84^{\circ} \pm 2^{\circ}\left(\mathrm{c} 0.1, \mathrm{H}_{2} \mathrm{O}\right)^{[6]}\right)$

Received: February 11, 2010

[1] E. Atherton, R. C. Sheppard, 'The Fluorenylmethoxycarbonyl Amino Protection Group', in 'The Peptides', Eds. S. Udenfriend, J. Meienhofer, Academic Press, New York, 1987, Vol. 9, p. 1.

[2] a) L. A. Carpino, G.Y. Han, J. Org. Chem. 1972, 37, 3404; b) F. M. F. Chen, N. L. Benoiton, Can. J. Chem. 1987, 65, 1224

[3] a) A. Paquet, Can. J. Chem., 1982, 60, 976; b) G. F. Sigler, W. D. Fuller, N. C. Chaturvedi, M. Goodman, M. Verlander, Biopolymers, 1983, 22, 2157; c) R. C. de L. Milton, E. Becker, S. C. F. Milton, J. E. H. Baxter, J. F. Elsworth, Int. J. Pept. Protein Res. 1987, 30, 431; d) L. Lapatsanis, G. Milias, K. Froussios, M. Kolovos, Synthesis 1983, 671.

[4] K. Arimitsu, K. Ichimura, J. Mat. Chem. 2004, 14, 336.

[5] M. Ueki, N. Nishigaki, H. Aoki, T. Tsurusaki, T. Katoh, Chem. Lett. 1993, 721.

[6] D. Lafquih Titouani, J.-P. Lavergne, P. Viallefont, R. Jaquier, Tetrahedron 1980, 36, 2961 . 